$\xi=-$ 国

\title{
Investigating Nano particles in Bioinformatic Analysis of the Brucella Genome for Indication and Differentation by qPCR
}

\author{
Alfiya V. Khammadova ${ }^{1}$, Nail I. Khammadov ${ }^{2}$, Maksim A. Kosarev², Konstantin A. Osyanin ${ }^{2}$ and Eduard A. Shura- \\ $\operatorname{lev}^{3}$ \\ ${ }^{1}$ Kazan Federal University, 18 Kremlyovskaya St., Kazan, 420008, Russian Federation \\ ${ }^{2}$ Federal Center for Toxicological, Radiation and Biological Safety, Nauchniy Gorodok-2, Kazan, 420075, Russian Federation \\ ${ }^{3}$ Kazan State Medical Academy - Branch Campus of Russian Medical Academy of Continuous Professional Education, 36 Butlerova St., \\ Kazan, 420012, Russian Federation \\ *Corresponding author E-mail: eduard.shuralev@mail.ru
}

\begin{abstract}
Based on the identified genes, the design of specific primers and probes for qPCR was made, which makes it possible to differentiate $B$. melitensis and B. abortus in a single reaction. For the differentiation of Brucella strains of the same species, the PCR method of multilocus VNTR analysis, optimized for uniform temperature conditions, is described. In addition, MLVA profiles for $B$. abortus and $B$. melitensis genomes are presented. All methods of indication and differentiation of Brucella species and strains are described in detail, which allows them to be used in the everyday work of any PCR laboratory dealing with brucellosis. Control of amplification in the indication of bacteria of the genus Brucella and determination of their belonging to B. abortus and B. melitensis species is recommended to be carried out using the plasmid DNA designed in this work.
\end{abstract}

Keywords: Brucella; genome; indication;nano particle; identification; qPCR; MLVA.

\section{Introduction}

There is a wide variety of species of the genus Brucella found in nature [1]: B. melitensis; B. abortus; V. suis; B. neotomae; B. ovis; B. canis; B. ceti; B. pinnipedialis; V. microti. To date, there are methods for laboratory diagnosis of brucellosis pathogens by molecular genetic methods [2]. New approaches are being introduced in the indication and identification of antigenic, vaccine and field Brucella spp. using multilocus sequence typing [3], Luminex bead-based suspension array [4], Multiple-locus variable number tandem repeat analysis (MLVA) [5]. The methodology of PCR for the detection of brucella in organs and tissues in postmortem studies is being improved [6]. In addition, there are differentiation methods for different strains of the same species, based on the Variable number tandem repeat analysis (VNTR) in the genome of brucella and other organisms [7]. Such studies supplement various databases on the genomes of infectious disease pathogens, one of which is BrucellaBase, which contains information on the genomes of more than 500 strains of Brucella [8]. In this paper we showed the available tools for gene diagnosis and differentiation of brucellosis pathogens.

\section{Materials and Methods}

For the genetic indication of bacteria of the genus Brucella and optimization of the methodology for their differentiation, a bioinformation analysis of the brucella genome of various species and strains was carried out, the general principles of bioinformatic analysis are similar to the development of primers for other biopathogens $[9,10]$. Nucleotide sequences for genome analysis were obtained from the National Center for Biotechnology Information (NCBI), in addition, "BLAST" and "VectorNTI 9.1.0" (Invitrogen Corporation) software utilities were used.

The design of oligonucleotide primers for quantitative real-time PCR (qPCR) was performed with the expectation of the possibility of multiplex amplification of various DNA markers in a single reaction. For the control of qPCR, a positive DNA sequence was developed comprising all of the desired marker nucleotide sequences. To amplify the chromosomal DNA, nucleic acids isolated from bacterial cultures of various brucella species (B. suis, $B$. abortus, B. melitensis) were used in the work. Isolation of nucleic acids was carried out by the method of magnetic sorption with a set of reagents "Magno-Sorb" variant 100-200, according to the instructions of the manufacturer - "Amplisens" (Russia).

For qPCR amplification, the following composition of the reaction mixture was used, per one sample: $1.5 \mu \mathrm{l}$ of a $25 \mathrm{mM} \mathrm{MgCl}_{2}$ solution; $2 \mu \mathrm{l}$ of a $2.5 \mathrm{mM}$ dNTP solution; $1.5 \mu \mathrm{l}$ of 10x PCR buffer; $0.5 \mu \mathrm{l}$ of $10 \mathrm{pM}$ probe solution for PCR; $10 \mathrm{pM}$ solution of forward and reverse primers of $0.5 \mu \mathrm{l} ; 0.5 \mu \mathrm{l}$ Taq polymerase; $5 \mu \mathrm{l}$ DNA and 3.5 deionized water. All the reagents were produced by Syntol (Russia). The final volume of the reaction mixture was 15 $\mu \mathrm{l}$. The probe for PCR, forward and reverse primers were applied individually (specifically) for each type of PCR (Table 1) and in the multiplex variant (indication of generic and specific DNA markers in one reaction mixture). The reaction mixture for each PCR in MLVA was identical, except for the probe for PCR, not used in this reaction, and 10x PCR buffer with EvaGreen stain (instead of the 10x PCR buffer described above) was used to monitor PCR amplification.

PCR was performed on a C1000 amplifier with an optical unit CFX96 (BioRad). The amplification program was as follows: (i) DNA denaturation at $95^{\circ} \mathrm{C}$ for 2 minutes; (II) 5 cycles consisting 
of: 10 seconds at $95^{\circ} \mathrm{C}, 30$ seconds at $60^{\circ} \mathrm{C}, 10$ seconds at $72^{\circ} \mathrm{C}$; (III) 40 cycles consisting of: 10 seconds at $95^{\circ} \mathrm{C}, 30$ seconds at $60^{\circ} \mathrm{C}, 10$ seconds at $72^{\circ} \mathrm{C}$. Detection of the result of PCR (fluorescence) occurs each 40th cycle of the third stage of the PCR, at $60^{\circ} \mathrm{C}$ via the FAM, Rox and R6G channels.

Electrophoresis was performed in a chamber for vertical electrophoresis (glass size $100 \times 100 \mathrm{~mm}$ ) manufactured by Helicon, with supply of $120 \mathrm{~V}$ into the chamber for 180-300 minutes. The buffer used for electrophoresis was from the "EF" kit (Central Research Institute of Epidemiology, Russia).

\section{Results and Discussion}

\subsection{Analysis of Brucella Genes}

The study on selecting the most informative genes for gene indication involved analysis of genomes of various Brucella strains of species $B$. abortus, B. melitensis. The alignment of the nucleotide sequence of different strains and isolates of each gene and the search for the genus-specific and species-specific sequences revealed optimal nucleotide sequences that can be successfully used for gene identification of bacteria of the genus Brucella and differentiation of Brucella species of interest to us (B. abortus and $B$. melitensis). Thus, for the indication of the genus Brucella, the gene BSCP31 (the sequence cipher in the gene bank - KX529834) was chosen, with a molecular mass of $1034 \mathrm{bp}$ localized in the first chromosome. The locus BAW_20982 with a molecular mass of $1220 \mathrm{bp}$ was chosen as the optimal display for B. abortus, the locus is located on the second chromosome at 1003355 to 1004575 bp (strain Wisconsin). For the indication of B. melitensis, the locus C0R52_12390 with a molecular mass of $482 \mathrm{bp}$, localized in the second chromosome at 906042 to 906524 bp (strain B3), showed to be the most specific, and was used for the further design of the primers and a probe.

\subsection{Design of Primers and Probes}

Based on the nucleotide sequence of the above marker loci, the design of primers and probes for PCR was performed (Table 1); the main criteria were: to achieve the most identical annealing temperature of the primers; minimum content of dimers and secondary structures in primers and probes; a minimum of guanine and cytosine at the 3 ' end of the primers; the absence of guanine at the 5' end of the probe.

Table 1:. Nucleotide sequence of primers and probes for PCR indication of brucella

\begin{tabular}{|c|c|c|}
\hline $\begin{array}{l}\text { Detectable } \\
\text { pathogen }\end{array}$ & $\begin{array}{l}\text { Primer / } \\
\text { probe en- } \\
\text { coding }\end{array}$ & 5 '-> 3' nucleotide sequence \\
\hline \multirow{3}{*}{$\begin{array}{l}\text { genus } \\
\text { Brucella }\end{array}$} & Bru F & tcgaatggctcggttgcca \\
\hline & Bru R & cgggtaaagcgtcgccagaa \\
\hline & Bru P & (Fam)cgatcaagtcgggcgctctgga(BHQ1) \\
\hline \multirow{3}{*}{ B. abortus } & $\begin{array}{l}\text { Bru abortus } \\
\text { F }\end{array}$ & gcaatcgtcgtattgccactataatcat \\
\hline & Bru abortus $\mathrm{R}$ & gacggcgcagttctcgaacaa \\
\hline & $\begin{array}{l}\text { Bru abortus } \\
\text { P }\end{array}$ & (Rox)ccgaaaggatcagcgtgccagaa(BHQ2) \\
\hline \multirow{3}{*}{$\begin{array}{l}B . \\
\text { melitensis }\end{array}$} & Bru meli F & tgcttggcacctcggaaacac \\
\hline & Bru meli R & cattcccgaaagccgatagagtttga \\
\hline & Bru meli P & (R6G)tgaagcgctgcagacaaattttgacttcc(BHQ2) \\
\hline
\end{tabular}

For the convenience of interpreting the results of PCR with the above primers and probes, the latter were labeled with various fluorescent stains, which are also indicated in Table 1, in parentheses. The characteristics of the primers and probes resulting from the design are indicated in Table 2.
Table 2:. Characteristics of the PCR-intended primers and probes

\begin{tabular}{|c|c|c|c|c|}
\hline $\begin{array}{l}\text { Detectable } \\
\text { pathogen }\end{array}$ & $\begin{array}{l}\text { Primer / probe } \\
\text { encoding }\end{array}$ & $\begin{array}{l}\text { Melting } \\
\text { point }\end{array}$ & $\begin{array}{l}\text { Number / } \\
\text { length of } \\
\text { dimers }\end{array}$ & $\begin{array}{l}\text { Number / } \\
\text { length of } \\
\text { secondary } \\
\text { structures }\end{array}$ \\
\hline \multirow[t]{3}{*}{$\begin{array}{l}\text { genus Bru- } \\
\text { cella }\end{array}$} & Bru F & $59.6^{\circ} \mathrm{C}$ & $5 / 3$ and 4 & $\begin{array}{l}2 / 3 \text { and } \\
4\end{array}$ \\
\hline & Bru R & $59.7^{\circ} \mathrm{C}$ & $2 / 3$ & 0 \\
\hline & Bru P & $65.1^{\circ} \mathrm{C}$ & $4 / 3$ and 4 & $1 / 3$ \\
\hline \multirow[t]{3}{*}{ B. abortus } & Bru abortus F & $59.5^{\circ} \mathrm{C}$ & $\begin{array}{l}7 / 3,4 \text { and } \\
6\end{array}$ & $\begin{array}{l}3 / 3 \text { and } \\
6\end{array}$ \\
\hline & Bru abortus R & $59.8^{\circ} \mathrm{C}$ & $4 / 4$ & 0 \\
\hline & Bru abortus $\mathrm{P}$ & $64.0^{\circ} \mathrm{C}$ & $1 / 4$ & 0 \\
\hline \multirow[t]{3}{*}{ B. melitensis } & Bru meli F & $59.6^{\circ} \mathrm{C}$ & $2 / 3$ & $1 / 3$ \\
\hline & Bru meli R & $60.2^{\circ} \mathrm{C}$ & $4 / 3$ & $1 / 3$ \\
\hline & Bru meli P & $66.6^{\circ} \mathrm{C}$ & $7 / 4$ and 6 & $1 / 4$ \\
\hline
\end{tabular}

As can be seen from Table 2, the developed primers are characterized by the same melting point $\left(59.73 \pm 0.23^{\circ} \mathrm{C}\right)$, which allows for amplification under unified reaction conditions (one amplification program), from one to seven dimers and secondary structures in primers and probes, without the formation of critical polyneomas for PCR. This in aggregate will allow the use of these primers and probes for the indication of the brucella DNA. Complementarity of the above primers and probes (Table 1) to the nucleotide sequences of the desired bacteria is shown in Figure 1.
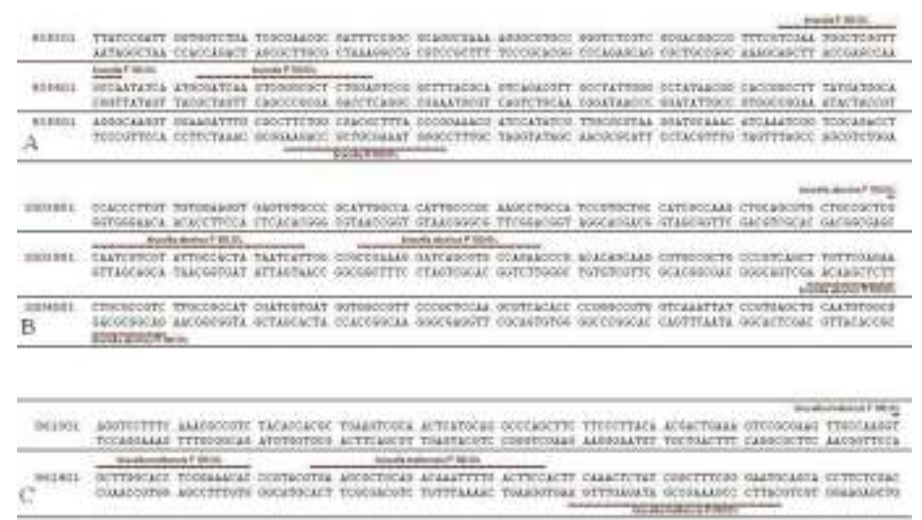

Fig. 1:. Complementarity of primers and probes for the indication of bacteria of the genus Brucella and species B. abortus and B. melitensis: A nucleotide sequence of the gene BSCP31 B. canis strain YH-C16; B nucleotide sequence of the locus BAW_20982 B. abortus strain Wisconsin; C - nucleotide sequence of the locus C0R52_12390 B. melitensis strain B3.

Primers and a probe for the indication of bacteria of the genus Brucella (in Figure 1 denoted as brucella F, R, P) amplify a gene characteristic of all genus species, including $B$. abortus and $B$. melitensis. Primers and a probe for the indication of bacteria belonging to species $B$. abortus (in Figure 1 denoted as brucella abortus F, R, P) are complementary only for different strains and isolates of this species. Primers and a probe for indicating bacteria belonging to species $B$. melitensis (in Figure 1 denoted as brucella melitensis F, R, P) are also characterized by specific amplification of bacteria of this species only.

\subsection{Design of Primers for Multilocus VNTR Analysis}

Marker loci for MLVA of bacteria of the genus Brucella were determined based on the analysis of VNTR loci of brucella presented on the website: http://mlva.upsud.fr/mlvav4/genotyping/query.php. The nucleotide sequence of VNTR loci is determined from the data published by S.O. Sadikalieva and co-authors [7]. For the convenience of the reaction, the primers were modified, the nucleotide sequences are shown in Table 3. This modification was performed to optimize the molecular weights of the amplification products obtained (for convenient analysis of the amplicon after Polyacrylamide Gel 
Electrophoresis (PAGE)) and unify the PCR conditions for ampli- fication of any locus.

Table 3:. Nucleotide sequence of primers and characteristics of amplicons for VNTR analysis of brucella

\begin{tabular}{|c|c|c|c|}
\hline Item & 5 -> 3 `sequence & Variable region & $\begin{array}{c}\text { The length of the amplicon } \\
\text { excluding the variable } \\
\text { repeats }\end{array}$ \\
\hline VBru4F & ctgacgaagggaaggcaa & \multirow{2}{*}{ gtagggca } & \multirow{2}{*}{147 bp } \\
\hline VBru4R & aggcgatctggagattatcg & & \\
\hline VBru6F & gggatgtggtagggtaatcg & \multirow{2}{*}{$\begin{array}{c}\text { ggatgggcagcagacgttaccegccegcccgcagccgcgaagcgagcgaggacggg- } \\
\text { caaaggcaaaagcgggcgtttgcctgggagggcaatgatggcacgcgagcgcatttatatctacgacaccacctcggc }\end{array}$} & \multirow{2}{*}{126 bp } \\
\hline VBru6R & gcgtgacaatcgactttttg & & \\
\hline VBru7F & agctgacggggaagaacat & \multirow{2}{*}{ ttccecta } & \multirow{2}{*}{125 bp } \\
\hline VBru7R & cctttttcagtcaaggcaaat & & \\
\hline VBru8F & attattcgcaggctcgtga & \multirow{2}{*}{ tccagcctgtcattctgt } & \multirow{2}{*}{279 bp } \\
\hline VBru8R & caaacagaaggttttccagct & & \\
\hline VBru9F & catggcggattcgttctt & \multirow{2}{*}{$\operatorname{actgccct}$} & \multirow{2}{*}{103 bp } \\
\hline VBru9R & gggagtatgttttggttgtacatag & & \\
\hline VBru11F & gctgttgatctgaccttgca & \multirow{2}{*}{ actgccattggccagaatcgtacctcgattagtaccaatgccaagggcgttgccgacaacaag } & \multirow{2}{*}{$195 \mathrm{bp}$} \\
\hline VBru11R & ccagacaacaacctacgtcct & & \\
\hline VBru16F & ggagtttttgttgctcaatgtt & \multirow{2}{*}{ aagggagt } & \multirow{2}{*}{$132 \mathrm{bp}$} \\
\hline VBru16R & gccatgtttccgttgatttat & & \\
\hline VBru18F & atgttagggcaatagggcag & \multirow{2}{*}{ gagtaagg } & \multirow{2}{*}{$137 \mathrm{bp}$} \\
\hline VBru18R & gatggttgagagcattgtgaag & & \\
\hline VBru19F & cgacccggaccatgtct & \multirow{2}{*}{ cacgat } & \multirow{2}{*}{$161 \mathrm{bp}$} \\
\hline VBru19R & tcaccgtaacgtcgtggat & & \\
\hline VBru21F & gctcatgcgcaaccaaa & \multirow{2}{*}{ ctattgcc } & \multirow{2}{*}{$120 \mathrm{bp}$} \\
\hline VBru21R & atctcgtggtcgataatctcatt & & \\
\hline VBru30F & tgaccgcaaaaccatatcc & \multirow{2}{*}{ agggcagt } & \multirow{2}{*}{113 bp } \\
\hline VBru30R & aatatgtgcagagcttcatgttc & & \\
\hline VBru42F & tcgcctcaactataccgtca & \multirow{2}{*}{$\begin{array}{l}\text { aagcgccatcatttttcgtgggtgacgatgacggggatcaagagatcaccccagtt- } \\
\text { gccgtcgecgttcccgtgttgccgaaggcacacaaagagaagaaacatggcggcgacggcaattgttga }\end{array}$} & \multirow{2}{*}{$162 \mathrm{bp}$} \\
\hline VBru42R & accgcaaaatttacgcatc & & \\
\hline VBru43F & tcaagcccgatatggagaat & \multirow{2}{*}{ ccgtttacccgc } & \multirow{2}{*}{152 bp } \\
\hline VBru43R & tccgcctgcccataaac & & \\
\hline VBru45F & tcatccttgcetctccetac & \multirow{2}{*}{ cggcggcggcgettcggg } & \multirow{2}{*}{$116 \mathrm{bp}$} \\
\hline VBru45R & gggtaaatatcaatggcttgg & & \\
\hline VBru55F & aggctgtttcgtcatgtcttt & \multirow{2}{*}{ gcggcactccacgectcttggttatatccetgecgtgect } & \multirow{2}{*}{183 bp } \\
\hline VBru55R & tctggcgttcgagttgttc & & \\
\hline
\end{tabular}

The nucleotide sequence may contain point replacements. The molecular weight of the amplified fragment consists of the length of the amplicon without taking into account the variable repeats and the value of a particular variable region, with the multiplicity represented in the genome of a particular strain. The analysis of the variable amount of such repeats (determination of the number of these repeats), respectively, was carried out by calculating the difference in the molecular weight of the amplicon (after electrophoresis) and the magnitude of the amplified fragment excluding the variable repeats (Table 3 ), the resulting digit was divided by the number of nucleotides of the variable region (the nucleotide sequence is represented in Table 3); an example of the calculation of the number of variable repeats is presented below. The typical profile of MLVA for some B. abortus and B. melitensis strains and isolates is presented at: http://vnivi.ru/images/mlva.xls.

A sample of the calculation of the number of variable repeats upon amplification of the "Bru4" locus, if: the molecular weight of the amplicon is $187 \mathrm{bp}$; the magnitude of the amplified fragment without taking into account the variable repeats $147 \mathrm{bp}$; nucleotide sequence of the $8 \mathrm{bp}$ variable region is "gtagggca". The number of variable repeats is calculated as follows: $187-147=40,40 / 8=5$. The number of variable repetitions of the locus "Bru4" is 5 .

\subsection{Design and Construction of Positive Control}

To verify the correctness of the design of the primers and the probe, the correct composition of the reaction mixtures in PCR and the amplification program, a positive control was created, presented as a plasmid DNA with a specific insert for amplification of bacteria of the genus Brucella and determining their belonging to B. abortus and B. melitensis (complementary developed primers and probes). The nucleotide sequence of the specific insert is an alternation of loci complementary to direct primers for indicating each of the three DNA markers, then alternation of the loci complementary to the probes to indicate each of the three DNA markers and the loci complementary to the reverse primers to indicate each of the three DNA markers. Thus, the original nucleotide sequence of all three marker regions is imitated. The specific insert created had the following nucleotide sequence: "5 tcgaatggctcggttgccagcaatcgtcgtattgccactataatcattgcttggcacctcgg aaacaccgatcaagtcgggegctctggaccgaaaggatcagcgtgccagaatgaagcgctgcagacaaatttgacttccttctggcgacgctttacccgttgttcgagaactgcgecgtctcaaactctatcggctttcgggaatg3'”. The complementarity of the primers developed and the positive control is illustrated in Figure 2.

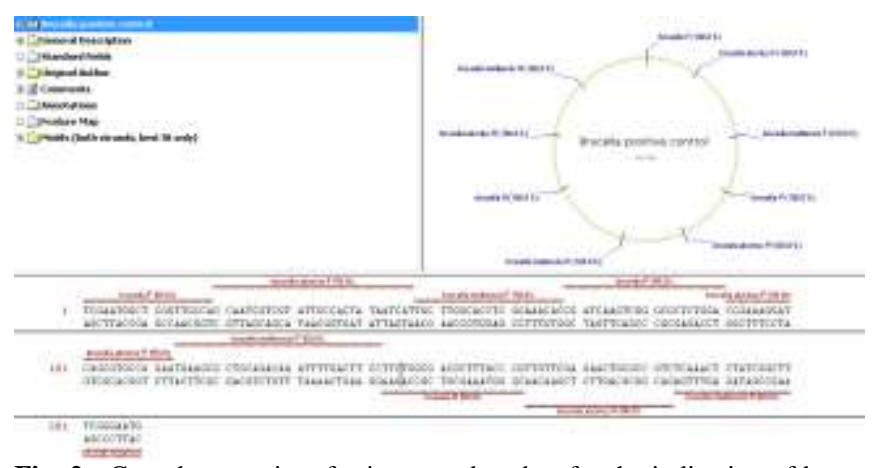

Fig. 2:. Complementarity of primers and probes for the indication of bacteria of the genus Brucella and species B. abortus and B. melitensis to the nucleotide sequence of the positive control

Synthesis and an insert into the plasmid vector "pAL2-T" were provided by Evrogen, Russia. As a result, PCR with this positive control accumulates amplification products of molecular weight from $162 \mathrm{bp}$ to $164 \mathrm{bp}$, which allows to control PCR (with any complex of oligonucleotide primers indicated in Table 1) both in electrophoretic format and in real time. 


\subsection{Polymerase Chain Reaction with Developed Primers and Probes}

The performance of all primers and probes is confirmed by amplification. Primers and probes for indicating bacteria of the genus Brucella and determining their belonging to $B$. melitensis and $B$. abortus were amplified from positive control DNA and from the DNA of vaccine strains of $B$. abortus and B. melitensis; the amplification result is shown in Figure 3.
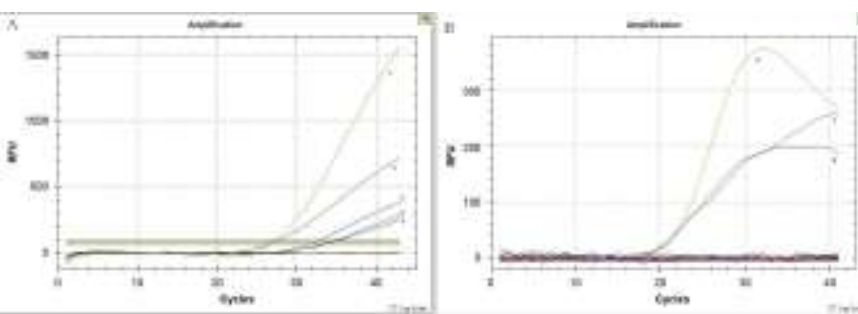

Fig. 3:. Amplification of marker brucella loci

Nomenclature: PCR with DNA matrix of B. suis, B. abortus and B. melitensis (A); PCR with a positive control DNA matrix at a concentration of $1 \mu \mathrm{g} / \mu \mathrm{l}(\mathrm{B})$; the PCR result for the Fam channel $(2,3$, $5,7)$; the PCR result for the Rox channel $(1,6)$; the PCR result for the R6G channel $(4,8)$; amplification of $B$. suis DNA (3); amplification of $B$. abortus DNA $(1,2)$; amplification of $B$. melitensis DNA $(4,5)$.

The PCR used a mixture of primers and probes to simultaneously show (in one tube) the bacteria of the genus Brucella and determine their belonging to B. abortus and B. melitensis. As a result of amplification with $B$. suis DNA, PCR was performed only with generic primers and a probe (via the FAM channel). Amplification with the B. abortus and B. melitensis DNA was successful not only for generic primers, but also for specific primers and probes (via Rox and R6G, respectively). Specific amplification occurred only with the desired DNA. With positive control DNA, amplification was successful in all three channels, which confirms their correct design.

The use of primers for MLVA was performed using a DNA of $B$. melitensis strain Rev.1 as DNA matrix; the amplification results (indicating the molecular weight of amplicons and the number of variable repeats) are shown in Table 4.

Table 4:. Amplification results for MLVA

\begin{tabular}{|l|l|l|}
\hline Locus & $\begin{array}{l}\text { Molecular mass of the am- } \\
\text { plicon }\end{array}$ & $\begin{array}{l}\text { Number of re- } \\
\text { peats }\end{array}$ \\
\hline VBru4 & 155 & 1 \\
\hline VBru6 & 390 & 2 \\
\hline VBru7 & 150 & 3 \\
\hline VBru8 & 330 & 3 \\
\hline VBru9 & 150 & 6 \\
\hline VBru11 & 260 & 1 \\
\hline VBru16 & 150 & 2 \\
\hline VBru18 & 170 & 4 \\
\hline VBru19 & 160 & 0 \\
\hline VBru21 & 150 & 4 \\
\hline VBru30 & 150 & 5 \\
\hline VBru42 & 410 & 3 \\
\hline VBru43 & 180 & 2 \\
\hline VBru45 & 150 & 2 \\
\hline VBru55 & 260 & 2 \\
\hline
\end{tabular}

Comparison of the MLVA profiles of different isolates and strains of brucellas allows us to establish in a relatively short time (2-3 days) the strain belonging to the analyzed species of brucella, and to find identical, similar or different isolates.

\section{Conclusion}

In the course of the research work the following conclusions were drawn:

1. As a result of the bioinformational analysis, DNA marker loci for indicating bacteria of the genus Brucella and determining their belonging to the species $B$. abortus and $B$. melitensis have been determined. The design of primers and probes for qPCR is made, which allows amplifying these loci.

2. Nucleotide sequences for MLVA are adapted for use in the conventional PCR laboratory settings, under the same conditions and modes of research.

3. A unique positive control, containing the nucleotide sequences of the indicated loci, has been created.

4. The described MLVA-technique allows for effective differentiation of different isolates and strains of brucella and their possible belonging to certain strains of brucella from genomic databases.

\section{Acknowledgements}

The work is performed according to the Russian Government Program of Competitive Growth of Kazan Federal University.

\section{References}

[1] Sankarasubramanian J., Vishnu U.S., Gunasekaran P., Rajendhran J. Identification of genetic variants of Brucella spp. through genomewide association studies. Infect Genet Evol., 2017, 56, 92-98, doi 10.1016/j.meegid.2017.11.016

[2] Bariev Y.A., Musiev D.G. Comparative sensitivity of PCR and serological reactions to brucellosis. Proceedings of Gorsky State Agrarian University, 2015, 52(1): 107-110

[3] Shome R., Krithiga N., Shankaranarayana P.B., Jegadesan S., Udayakumar S.V., Shome B.R., Saikia G.K., Sharma N.K., Chauhan H., Chandel B.S., Jeyaprakash R., Rahman H. Genotyping of Indian antigenic, vaccine, and field Brucella spp. using multilocus sequence typing. J Infect Dev Ctries, 2016, 10(3): 237-244, doi: $10.3855 /$ jidc. 6617

[4] Lusk Pfefer T.S., Timme R., Kase J.A. Identification of Brucella genus and eight Brucella species by Luminex bead-based suspension array. Food Microbiol., 2018, 70: 113-119, doi: 10.1016/j.fm.2017.09.015

[5] Daugaliyeva A., Sultanov A., Usserbayev B., Baramova S., Modesto P., Adambayeva A., Acutis P.L., Peletto S. Genotyping of Brucella melitensis and Brucella abortus strains in Kazakhstan using MLVA-15. Infect Genet Evol., 2018, 58: 135-144, doi: 10.1016/j.meegid.2017.12.022

[6] Çiftci A., İça T., Savaşan S., Sareyyüpoğlu B., Akan M., Diker K.S. Evaluation of PCR methods for detection of Brucella strains from culture and tissues. Trop Anim Health Prod., 2017, 49(4): 755-763, doi: 10.1007/s11250-017-1256-1

[7] Sadikalieva S.O., Strochkov V.M., Orynbaev M.B., Shorayeva K.A., Espembetov B.A., Sansyzbay A.R., Sultankulova K.T. Molecular-genetic typing of bacteria of genus Brucella circulated in the Republic of Kazakhstan. Vestnik Bashkirskogo Universiteta, 2017, 22(2): 403-408

[8] Sankarasubramanian J., Vishnu U.S., Khader L.K., Sridhar J., Gunasekaran P., Rajendhran J. BrucellaBase: Genome information resource. Infect Genet Evol., 2016, 43: 38-42, doi 10.1016/j.meegid.2016.05.006

[9] Ndayishimiye E.W., Khammadov N.I., Osyanin K.A., Faizov T.Kh., Shuralev E.A., Mukminov M.N. Bioinformatic analysis of oligonucleotides for molecular genetic indication of honey-bee aspergillosis and ascospherosis pathogens. Veterinarny Vrach, 2015, 2: 3-9

[10] Khammadova A.V., Shuralev E.A., Khammadov N.I., Oumarou B.M., Faizov T.K., Mukminov M.N. Design of primers for identification of honey bee viruses in multiplex-PCR. Astra Salvensis, 2017, 5(S1): 481-489 